\title{
STRANGE FRUIT OF THE CRETACEOUS POPPY
}

SMITH, Una R., Dept. of Biology, Yale University, New Haven, CT 06520-8104, USA.

The first two fragmentary specimens of the Cretaceous poppy were collected in 1872 . In 1873, they were described as (1) the basal leaf rosette of Eriocaulon (an extant monocot, the common pipewort), and (2) the leafy twig of Eucalyptus (also extant and common). In the early 1900's, several less fragmentary specimens were described as (3) Palaeoaster, the supposedly primitive reproductive organ of an angiosperm of unknown affinity, and (4) the fruit of an unknown species in the family Sterculiaceae.

This fossil, now known as Palaeoaster, is the capsular fruit of an extinct species of the Papaveraceae (Smith 1995). Its known stratigraphic range, based on 200 specimens from 50 localities, extends 11 million years from the Campanian Fruitland Formation to within one meter of the Cretaceous-Tertiary boundary in the Maastrichtian Hell Creek Formation. Its known geographic range extends from northern New Mexico to northern Montana and from eastern Utah to the Dakota badlands.

Palaeoaster is the first good fossil evidence of the Papaveraceae prior to the Quaternary. Recent molecular phylogenetic evidence suggests that, contrary to traditional interpretation, the Papaveraceae are the most ancient family in the angiosperm subclass Ranunculidae. The well-documented presence of Palaeoaster in the Cretaceous supports this hypothesis. Phylogenetic placement of the Papaveraceae near the base of the Ranunculidae, and of the Ranunculidae near the base of the eudicot angiosperm clade, implies that (1) conventional theories about the evolution of eudicot angiosperms must be reconsidered and (2) study of the Papaveraceae, including Palaeoaster, may be of particular value in this regard.

Palaeoaster has been collected from two Tyrannosaurus rex localities, several marine invertebrate localities, and numerous rich plant fossil localities. Three specimens have been found on the surface, weathered but intact. Five excellent intact specimens (four of them permineralized) have been collected by amateurs. Many additional specimens may have been misidentified as leaves, seeds, or nuts, or remain unidentifed in numerous collections, both amateur and professional. Palaeoaster is easy to identify by eye in the field, by the presence of two distinctive features on each valve of the fruit capsule. These features are described in a handout available at the poster display, and illustrated here in actual size.

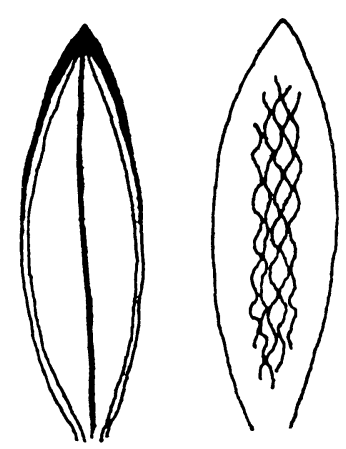

part and counterpart

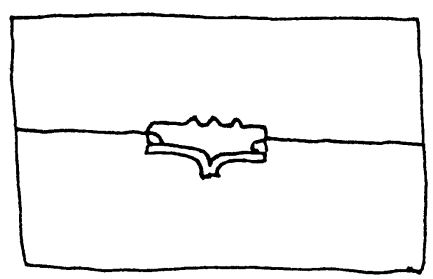

$\mathrm{X}$-section in matrix

Smith, U. R. 1995. Discovery of poppy fruits (Papaveraceae) in the Late Cretaceous. Palaeontology Newsletter, 28:22. 